\title{
Coach-Athlete Relationship Questionnaire (CART-Q) for Use with Deaf Athletes: Validity and Reliability Study
}

\author{
Mustafa Yasar Şahin ${ }^{\star *}$, Berrak F. Firat', Pinar \\ Şezer ${ }^{2}$ \\ ${ }^{1}$ Graduate School of Health Sciences, Department of Physical \\ Education and Sport, Gazi University, Ankara, Turkey \\ ${ }^{2}$ Graduate School of Educational Sciences, Department of \\ Measurement and Evaluation, Ankara University, Ankara, \\ Turkey \\ Study Area: Ankara, Turkey \\ Coordinates: $39^{\circ} 55^{\prime} 48^{\prime \prime} \mathrm{N} 32^{\circ} 51^{\prime} \mathrm{Oo} " \mathrm{E}$
}

\section{Introduction:}

One of the most important factors in human relationships is communication. Cuceloglu (2018) defines communication as "an exchange of related messages between two units" and the bilateral understanding that comes after. Cuceloglu (2018) does not limit the exchange of messages to just speech but instead describes it as such, "humans' ability to relay information, their feelings and their thoughts to one another through various methods (gestures, eye contact, body language, touch, facial expressions, etc.)". Communication, which is vital and necessary in all aspects of life, is also a factor that impacts the outcomes in sports. Communication is an interactive, two-way process that takes place between the athlete and the coach, and the athlete's ability to understand, apply, develop and continue their career depends on them finding a coach with whom they can communicate and relate to in a positive fashion (Altintas et al., 2012).

Jowett \& Ntoumanis (2003) state that in the physical and psychological development of the athlete and their relationship with the coach, the coach is the one who determines the situation and the athlete takes a central role. According to Philippe \& Seiler (2006), the coach-athlete relationship is one of the factors that are important for performance.

In their study, Jowett \& Ntoumanis (2004, p.157) focused on "identifying emotions" in the relationship between the coach and the athlete through the structures of closeness, commitment, and complementarity. According to this point of view:

Closeness is related to the emotions and feelings

\section{Abstract}

This study was based on the questionnaire filled-up by 60 $\mathrm{DHOH}$ national athletes. Confirmatory factor analysis was applied to evaluate the structural validity of the questionnaire which was made up of 11 items and 3 derived constructs (closeness, commitment, complementarity). The findings were in line with the three-factor structure of the original questionnaire. The "Coach-Athlete Relationship Questionnaire" was a valid and reliable measurement tool evidenced as an output of this study.

Key words: Physical disbility \& sports, Validity, Reliability Scale

between the coach and the athlete, and these feelings can be defined as their perceptions and experiences. According to the research 'closeness' emerges with the development of interpersonal feelings such as respect, trust, and love (Jowett \& Cockerill, 2003; Jowett \& Meek, 2000a, 200ob). Closeness is also an indicator of a positive relationship, opens a path to good communication, and can be an effective problem-solving strategy. Thus, while trust and respect are fundamental for a successful coach-athlete relationship, a lack there of may cause a lack of motivation in daily practice or other problems in the relationship (Trzaskoma-Bicserdy et al., 2007).

Commitment is also related to sustaining a positive coach-athlete relationship (Jowett \& Ntoumanis, 2004), and commitment requires common success, believing in goals, and reciprocal needs. However, the intensity of this relationship can result in a difficult and stressful process. The importance of actions related to commitment is to prevent low performance and negative behavior, to sustain balance, and also nurture a sense of unity between the coach and the athlete (Jowett \& Cockerill, 2003; Jowett \& Meek, 2000a.)

Complementarity can be described as the level of compatibility between the coach and the athlete. Just as in closeness and commitment, complementarity is also a factor that affects performance. For example, the response of the athlete to the coach's efforts during the practice can be considered an indicator of complementarity.

The three dimensions that include the feelings described above (closeness, commitment, and complementarity) are the scale for CART-Q, developed by Jowett and Ntoumanis (2004) to identify the nature of the

*Corresponding Author:mysahin@gazi.edu.tr 
coach-athlete relationship. This scale includes 11 items or 'relationship criteria' that are short and easy to use, and which are related to emotional (closeness), cognitive (commitment), and behavioral (complementarity) aspects of the relationships. Questions 3,5,8, and 9 deal with closeness; 1,2 and 6 with commitment, 4,7,10, and 11 with complementarity (Jowett \& Ntoumanis, 2004; Jowett, 2009).

The coach-athlete relationship questionnaire (CART$\mathrm{Q})$, the ${ }_{3} \mathrm{C}$ model was first qualitatively and quantitatively used in England, later in the USA, Belgium, China, Greece, Great Britain, Spain, Sweden, Hungary, Turkey and Brazil (Yang \& Jowett, 2012; Altintas et al., 2012). This questionnaire presents sufficient psychometric qualities in validity and reliability and is used as a universal tool for evaluating coach-athlete relationships. The questionnaire has been used in studies in Turkey, but these studies were conducted using hearing athletes. In one of the limited studies conducted on this topic and aimed towards hearing athletes in Turkey, Altintas et al., (2012) CART-Q was adapted with a 'validity and reliability' study and Asçi et al., (2015) the relationship was analyzed based on work, school, and home relationships in their article titled "The Role of the Athlete's Personality in the Coach-Athlete Relationship". In the study, Asçi et al., (2015) stated that athletes were optimistic, sincere, comfortableand talkative individuals that they perceived more support and less conflict in relationships and that, within this context, the social, energetic, interactive nature of extroverted individuals may enhance the quality of the relationship.

In another study, coach adequacy was researched and one factor that emerged in the findings was motivation (Feltz et al., 1999). Güven (1996) also supported this by observing the impact of positive words from coaches on the performance and success of the athlete. It is natural that Deaf athletes also require the same motivation. As is shown in this study, it is clear that the coach must motivate the athlete. This is only possible through good communication.

Looking at the research on the coach-athlete relationship, there were no studies on $\mathrm{DHOH}$ athletes with whom there is a communication barrier and who represent a different culture. This study on sports for the Deaf ascertains the impact of communication, cultural differences, and the coach-athlete relationship. Taking a brief look at applications of sports for the Deaf, according to the International Committee of Sports for the Deaf (ICSD) rules, participants must undergo an audiogram and the loss of hearing in both ears must be above $55 \mathrm{dBs}$ (ICSD website, 2020). Since the rules state that athletes can participate if they have at least $55 \mathrm{dBs}$ of hearing loss, athletes with some hearing loss can also participate alongside Deaf athletes. This is why there is a mixed profile of athletes who are Deaf and hard of hearing. The most significant difference between Deaf people and people who are hard of hearing is the difference in 'understanding and perception' that comes about because of hearing. In this case, the coach must work even harder to approach different athletes in different ways. When evaluating the coachathlete relationship, the results may vary between athletes who are Deaf and/or hard of hearing (DHOH). The reason for this difference is that the hard-of-hearing athlete, who can hear albeit partially, will be able to understand and apply the coach's instructions whereas this will not be the case for the Deaf athlete.

The main tools of communication used by Deaf individuals are sign language, body language, written description, and interpreters. Those who are hard of hearing can also use verbal communication via devices such as hearing aids, cochlear implants, etc. As long as the athlete and the coach facilitate the healthy communication, they can understand one another and reach their goals. Lack of adequate communication results in a variety of problems, the most important of which is the athlete being able to follow the coach's instructions. All sports have their unique technical terms and language. Even in cases where sign language is used to instruct the Deaf athlete, it has been observed that the athlete has comprehension issues which in turn harms the athlete.

Like all other socio-cultural groups, the Deaf community has its own unique culture, identity, and common language (sign language). According to Yazoglu (2005) "language is the most fundamental tool for the formation and development of culture". In this context, language enables the formation of a community and historical continuity and signifies that one is part of the culture of a community that speaks the same language (Yazoglu, 2005). Sign language is a Deaf person's first language and method of communication, which also provides them with their own culture. Deaf people are a part of the countries they live in and use sing language, which is a visual language, with the support of the language used where they reside. In this context, the Deaf community in Turkey use Turkish Sign Language with the support of Turkish to communicate. This is why due to the structure of their language; Deaf people must be considered a subculture of Turkey.

$\mathrm{DHOH}$ individuals participating in performance sports at a professional level need to pay attention to the strategies, instructions, and suggestions with the support of their coaches, and achieving this goal requires communication.

Good communication in coach-athlete relationships motivates the athlete, enhances their performance, and makes them more successful. Thus, seminars for coaches about the characteristics of Deaf athletes and the behavior of coaches, workshops for athletes on terminology and branches of sports will take the coach-athlete relationship 
to the next level. The Deaf community is different in language and culture, they do not see themselves as part of the hearing (Olympic) or disabled (Paralympic) areas of sport, Deaf sports also have their limitations. In this context, this study aims to adapt the Coach-Athlete Relationship Questionnaire (CART-Q) into Turkish for Deaf athletes and analyze the validity and reliability of the scale to add the scale to the national literature in the field.

\section{Materials and Methods:}

In this study, the athlete version of the (CART-Q) was used as a data collection tool for Deaf athletes. The CART-Q is made up of 11 items and 3 derived constructs. Three items $(1,2$ and 6$)$ measure commitment, four items $(3,5,8$, and 9$)$ measure closeness, and four items $(4,7,10$, and 11$)$ measure complementarity. All 11 items were reviewed and changes were made to items when necessary without changing the meaning of the item (e.g. "I trust my coach" "I am ready to do my best when my coach is training me"). All items were measured on a 7-point Likert scale from 1 (Completely Disagree) to 7 (Completely Agree).

National athletes in 24 sports active in the Turkish Deaf Sports Federation (TIESF) make up the population of the study and the sample is made up of 60 randomly chosen athletes in this group over the age of 18 .

CART-Q: this questionnaire, developed by Jowett \& Notumanis (2004) to evaluate the relationship between coach and athlete, is a self-report instrument for sports. The questionnaire is made up of 11 questions and a 7-point Likert scale. The questions contain three derived constructs; Closeness (4 items), Commitment (3 items), and Complementarity (4 items).

Closeness: refers to statements that describe an athlete's feelings of closeness to their coach including love, respect, and trust. (e.g. I respect my coach).

Commitment: refers to the commitment of the athlete to their coach, the continuity of this commitment, mutual willingness in the relationship, and a positive goal (e.g. I am committed to my coach).

Complementarity: refers to the athlete pursuing and taking responsibility for common goals, and statements of friendship that refer to mutual cooperation (e.g. When I am coached by my coach, I am responsive to his/her efforts).A similar study was conducted by Asçi et al., $(2012,2015)$ and validity and reliability were approved from the perspective of the $\mathrm{P}<1$ value.

Data Collection: the CART-Q was adapted for Deaf athletes following extensive discussions, taking into account the limited literacy and cultural differences of Deaf athletes. Later, the authors of the questionnaire were e-mailed to acquire consent for use of the questionnaire. In the process of adapting the items on the questionnaire into Turkish, five people with a high level of English and experience in sport science translated the items into
Turkish. Then the statements were translated back into English, compared against the original, and adapted when necessary. The pen and paper model of the Turkish translation of the CART-Q was filled out by 5 Deaf athletes. Next, misunderstandings were identified. The items that were misunderstood $(2,6,7,9,10$, and 11) were rephrased in a way the Deaf athletes could understand but that did not change the meaning of the item. At this stage, help was received from an assessment and evaluation specialist. The original item and the rephrased version can be seen below.

Item 2

Original: I am committed to my coach

Deaf version: I do not think I will work with someone other than mycoach

Item 6

Original: I think that my sports career is promising with my coach

Deaf version: I think I will be successful in my sports career with the support of my coach

Item 7

Original: When I am coached by my coach, I am responsive to his/her efforts

Deaf version: I do my best to do what my coach tells me to do in practice

Item 9

Original: I appreciate my coach's sacrifices to improve performance

Deaf version: I appreciate the work my coach does for me

Item 10

Original: When I am coached by my coach, I am ready to do my best

Deaf version: I try to do my best for my coach in practice

\section{Item 11}

Original: When I am coached by my coach, I adopt a friendly stance

Deaf version: My coach and I are like friends when we work

The rephrased statements were tested on 10 Deaf athletes in the second round. When the questionnaire had been finalized, it was filled out by 60 volunteer athletes on the online program. 40 athletes who were observed to have difficulty in understanding were supported in answering the questions in person orvia video calls.

Data Analysis: The three-factor structure (closeness, commitment, complementarity) of the CART-Q, which was identified as fulfilling the assumption of normality, was tested using confirmatory factor analysis. Confirmatory Factor Analysis (CFA), which is used to show if predetermined relationship patterns are confirmed by the data. This method is used as an effective method of testing the structural validity of a structurally predetermined measurement tool in the process of this tool being adapted to a different culture. CFA is regularly used by researchers to evaluate the validity of structures (Stapleton, 1997). According to Hair et al., (2010) evaluating the structural validity of a proposed evaluation model is one of the main uses of CFA. Thus, CFA was used to test the compatibility of the three-factor model developed by Jowett \& Ntoumanis 
(2004) to evaluate the relationship between coach and athlete) and the Turkish sample. This evaluation model was analyzed using LISREL (Jöreskog \& Sörbom, 2006).

Table 1. Comparative Table of Fit Index Values and Analysis Values

\begin{tabular}{llll}
\hline & $\mathrm{a}$ & $\mathrm{b}$ & $\mathrm{c}$ \\
\hline$\chi^{2}$ & p>0.05 & $\chi^{2}(59)=137.28$ & $\chi^{2}(59)=120.05$ \\
NC & $=\mathbf{2 . 5}=$ perfect fit & 2.32 & 2.03 \\
CFI & $=0.90$ = goodfit & 0.97 & 0.98 \\
RMSEA & $=0.05=$ perfectfit & 0.07 & 0.06 \\
NFI & $=0.90=$ goodfit & 0.94 & 0.95 \\
NNFI & 1=perfectfit & 0.97 & 0.98 \\
IFI & $=0.95$ & 0.96 & 0.97 \\
GFI & $=0.90$ & 0.90 & 0.91 \\
AGFI & $=0.90$ & 0.88 & 0.89 \\
\hline
\end{tabular}

a-Fit Index Values; b-Values Before Modification; c-Item 8-9 Values After Modification

Table-1 shows that the fit index values reached at the end of analyses point towards the fact that the data acquired from the model and the sampling are sufficiently compatible. Looking at the LISREL modification indices, it is seen that the modifications made to items 8 and 9 would result in a significant decrease of 17.23 in the Chi-Square (x2). Modifications to items 8 and 9 increased the fit between the data and the model.

Table-2: Parameter Values Related to the CART-Q

\begin{tabular}{|c|c|c|c|}
\hline \multicolumn{4}{|c|}{ Derived Ştructures } \\
\hline $\begin{array}{l}\text { Questionnaire } \\
\text { Items }\end{array}$ & $\mathrm{t}$ value & $\begin{array}{l}\text { Item Total } \\
\text { Correlation }\end{array}$ & $\mathrm{R}_{2}$ \\
\hline \multicolumn{4}{|l|}{ CLOŞENEŞŞ } \\
\hline 3 & 11.92 & 0.49 & 0.46 \\
\hline 5 & 9.11 & 0.44 & 0.40 \\
\hline 8 & 12.14 & 0.52 & 0.66 \\
\hline 9 & 12.75 & 0.53 & 0.72 \\
\hline \multicolumn{4}{|c|}{ COMMITMENT } \\
\hline 1 & 13.44 & 0.66 & 0.50 \\
\hline 2 & 11.55 & 0.64 & 0.52 \\
\hline 6 & 10.45 & 0.68 & 0.52 \\
\hline \multicolumn{4}{|c|}{ COMPLEMENTARITY } \\
\hline 4 & 11.55 & 0.63 & 0.54 \\
\hline 7 & 10.19 & 0.53 & 0.44 \\
\hline 10 & 11.18 & 0.62 & 0.62 \\
\hline 11 & $9 \cdot 91$ & 0.60 & 0.44 \\
\hline
\end{tabular}

Parameter values related to the evaluation model are presented in Table 2. According to CFA results, the validity of the item structure relationship with no changes made to any item was supported by the three derived structures and 11 items on the questionnaire. Within the scope of structural validity, correlation coefficients were used to examine the relationships between the derived structures. The fact that three factors that were thought to define the questionnaire used in this study were verified by CFA and also that correlation estimations between the factors were high, show that there is exceptional validity (Campbell \& Fiske, 1959).

The reliability of the CART-Q was analyzed by calculating the item-total correlation and internal consistency coefficient. The internal consistency coefficient (Cronbach Alpha) of the questionnaire was calculated as 0.90. Table-2 shows the item-total correlation. The internal consistency coefficient of the derived structures Closeness, Commitment, and Complementarity were calculated as $0.81,0.84$, and 0.83 respectively. It was identified that the item-structure relationships of the three derived structures and 11 items in the CART-Q are reliable.

\section{Discussion:}

As a result of the analyses conducted during the adaptation of the questionnaire, it is proposed that the threedimensional (closeness, commitment, and complementarity) CART-Q and the data obtained from the Turkish Deaf Athletes sample are compatible. In this context, it can be said that there is no issue with using the questionnaire in the national literature. According to Büyüköztürk et al., (2017) items, 0.30 or higher in the interpretation of item-total correlation significantly differentiate the individuals based on the quality being measured. When we evaluate the results of the analysis with this in mind, it was seen that the version of the CART-Q adapted for Deaf athletes showed values of 0.44-0.68, and these values are significantly differentiated. Also, an examination of the Cronbach alpha values of the derived structures of the questionnaire shows that they are 0.81 , 0.84 , and 0.83 . It was seen that these values were between 0.80-1.0o which are described as perfect by Alpar (2001).

Up until now, research on coach-athlete relationships was conducted on elite or Olympic athletes (Jowett \& Cockerill, 2003; Adie \& Jowett, 2010). Schruijer \& Vansina (2002) examined the coach-athlete relationship by looking at the characteristics of leadership with the coach as a leader. However, according to Jowett \& Ntoumanis (2004), since leadership and relationship variables are not enough to impact the result, these concepts should be dealt with together and in a multifaceted fashion. They stated that in competitive sports strong task complementarity is more important than coach leadership and social complementarity of coach-athlete relationship variable (Carron et al., 2002; Mullen \& Copper, 1994; Williams \& Widmeyer, 1991).

As can be seen in the study by Altintas et al., (2012), similar results were obtained by Jowett \& Ntoumanis (2004) when they applied the questionnaire to 80 coaches and 134 athletes. Just as is the case in interpersonal relationships, the quality of personal experiences of the athletes and the coaches are one of the factors that impact and decide sportive performance in the coach-athlete relationship process (Jowett \& Cockerill, 2003; Poczwardowski et al., 2002; Wylleman, 2000).

We saw that this approach which is conceptualized as a coach-athlete relationship, at its core, focuses on a bilateral relationship in which quality and efficiency are tied to the 


\section{ORIGINAL ARTICLE}

coach. However, it is stated that all parties in the relationship (coach-athlete) have mutual responsibilities. The factor that affects skill and performance is up to the working relationship. In this relationship, the development of the coach and the athlete includes factors such as mutual support, help, guidance from the coach, verbal instruction, the athlete listening to the instructions, motivation, following the leader, acceptance, etc. (Jowett, 2017).

\section{References:}

Adie, J.W. \& Jowett, S. (2010): Meta-Perceptions of the coachathlete relationship, achievement goals, and ýntrinsic motivation among sport participants. L. Appl. Social Psychol., 40(11):27502773

Alpar, R. (2001): Şpor Bilimlerinde Uygulamalý Ýstatistik. Ankara: Nobel Yayýn Daðýtým.

Altintap, A., Çetinalp, Z.K. \& Apçi, F.H. (2012): Antrenör-sporcu ilipkisinin deðerlendirilmesi: geçerlik ve güvenirlik çalýpmasý. Spor Bilimleri Dergisi, 23(3):119-128.

Apçi, F.H., Kelecek, S. \& Altintap, A. (2015): The role of personality characteristics of athletes in coachathlete relationships. Perceptual and Motor Skills, 121(2):399-411.

Büyüköztürk, P. (2017): Şosyal bilimler için veri analizi el kitabi. Ankara: Pegem A.

Campbell, D.T. Fiske, D.W. (1959): Convergent and discriminant validity by the multitrait-multi-method matrix. Psychological Bulettin, 56(2):81-105.

Carron, A.V., Colman, M.M., Wheeler, J. \& Stevens, D. (2002): Cohesion and performance in sport: A meta analysis. J. Sport Exer. Psychol., 24(2):168-188.

Cüceloðlu, D. (2018): Öðretmenim bir bakar misin. Ýstanbul: Final Kültür Sanat Yayýnlarý.

Feltz, D.L., Chase, M.A., Moritz, S.E. \& Sullivan, P.J. (1999): Development of the multidimensional coaching efficacy scale.J.Edu. Psychol., 91.

Güven, Ö. (2006): Beden eðitimi ve spora katýlýmda aile faktörü. Sosyal Politika Çalýpmalarý Dergisi, 10(10):81-90.

Hair, J.F., Black, W.C., Babin, B.J. \& Anderson R.E. (2010): Multivariate Data Analysis. Seventh Edition, Pub. by: Pearson: New Jersey.

International Committee of Şport for the Deaf (ICSD) (2020, September 21). Version 5 Revised 14 March 2018.

Jowett, S. \& Meek, G.A. (200oa): A case study of a top-level coachathlete dyad in crisis (abstract). L. Sports Sci., 18:51-52.

Jowett, S. \& Meek, G. (20oob): Coachathlete relationships in married couples: an exploratory content analysis. The Sport Psychologist, 14:157175.

Jowett, S. \& Ntoumanis, N. (2003): The Greek coach athlete relationship questionnaire (GrCART-Q): Scale construction and validation. Int. J. Sport Psychol., 34:101124.

Jowett, S. \& Cockerill, I.M. (2003): Olympic medalists' perspective of the athlete-coach relationship. Psychol. Sport Exer., 4:313331.

Jowett, S. \& Ntoumanis, N. (2004): The coach-athlete relationship questionnaire (CART-Q): Development and initial
Ambient Science, 2020: Vol. 07(Sp1); 270-274 DOI:10.21276/ambi.2020.07.sp1.oa37

validation. Scandinavian J. Med. ESci. Sports, 14:245257.

Jowett, S. (2007): Interdependence analysis and the $3+1 \mathrm{Cs}$ in the coach-athlete relationship. In S. Jowett and D. Lavallee (Eds.), Social psychology in sport (pp. 1527). Champaign, IL: Human Kinetics.

Jowett, S. \& Poczwardowski, A. (2007): Understanding the coach-athlete relationship. In S. Jowett and D. Lavallee (Eds.), Social psychology in sport (pp. 314). Champaign, IL: Human Kinetics.

Jowett, S. (2009): Validating coacheathlete relationship measures with the nomo-logical network. Measurement Physic. Edu. Exer. Sci., 13:1e18.

Jowett, S. (2017): Coaching effectiveness: The coachathlete relationship at its heart. Curr. Opin. Psychol., 16:154-158.

Jöreskog, K.G. \& Sörbom, D. (2006): LISREL 8.8o. Chicago: Scientific Software International.

Lehmann, D.R. (1988): An Alternative Procedure for Assessing Convergent and Discriminant Validity. Appl. Psychologic. Measurement, 12(4):411-423.

Mullen, B. \& Copper, C. (1994): The relation between group cohesiveness and performance: An integration. Psychologic. Bulletin, 115(2):210.

Philippe, R.A. \& Seiler, R. (2006): Closeness, co-orientation and complementarity in coachathlete relationships: What male swimmers say about their male coaches. Psychol. Sport Exer., $7(2): 159-171$.

Poczwardowski, A., Barott, J.E. \& Henschen, K.P. (2002): The athlete and coach: Their relationship and its meaning. Results of an interpretive study. Int. J. Sport Psychol., 33(1):116-140.

Schruijer, S. \& Vansina, L. (2002): Leader, leadership and leading: from individual characteristics to relating in context. $L$. Organizational Behav, 23:869-874.

Stapleton, C.D. (1997): Basic concepts and procedures of confirmatory factor analysis. Report (https://files.eric.ed.gov/fulltext/ED407416.pdf)

Trzaskoma-Bicserdy, G., Bognar, J., Revesz, L. \& Geczi, G. (2007): The coachathlete relationship in successful Hungarian individual sports. Int. J. Sports Sci. Coach., 2:485495.

Williams, J.M. \& Widmeyer, W.N. (1991): The CohesionPerformance Outcome Relationship In a Coactlng Sport. I. Sport Exer. Psychol., 13(4):364-371.

World Federation of the Deaf (WFD) (2020, September 21) https://wfdeaf.org/

Wylleman, P. (2000): Interpersonal relationships in sport: uncharted territory in sport psychology research. Int. J. Sport Psychol.,31:555-572.

Yang, S.X. \& Jowett, S. (2012): Psychometric properties of the Coache Athlete Relationship Questionnaire (CART-Q) in seven countries. Psychol. Sport Exer., 13:36-43.

Yazoðlu, R. (2005): Dil-kültür ilipkisi. Muhafazakâr Düpünce Dergisi, 2(5):123-143. 